\title{
Dentate Gyrus Status and Seizure Outcome: Does a Relationship Exist or Not?
}

\author{
Gianluca Marucci
}

\section{To the Editor}

In the last years an increasing interest in dentate gyrus (DG) abnormalities has emerged. Several studies investigated morphologic features of granular cell pathology (GCP) [1-3] and neurogenesis in the human DG, considering that aberrant growth of neural stem cells could be involved in different neurologic and psychiatric diseases.

In particular, in 2009 [1], a classification system has been elaborated for GCP, recognizing three different histologic patterns: no-GCP (normal granule cell layer), GCP type 1 (substantial granule cell loss) and GCP type 2 (various architectural abnormalities in granule cell layer, mainly granule cell dispersion (GCD)). Since then, some efforts to investigate a possible association between the postsurgical seizure outcome and GCP have been made [2-4] but no unambiguous results have been reported, and attempts to clarify this issue could be useful.

Some of these papers $[2,3]$ provided evidence that GCD does not appear to have any influence on outcome following surgery. Thus, they demonstrated that a statistically significant correlation between seizure outcome and GCD, that is a subtype of GCP type 2 , has not been observed.

On the contrary, in those studies in which the overall subtypes of DG abnormalities (GCP type 1 and GCP type 2) have been considered $[1,4]$ in comparison to cases with normal granule cell layer, the authors observed that "the association between favorable postsurgical outcome and granule cell pathology (Type 1 or Type 2) was statistically significant $(\mathrm{P}=0.028)$ " [1].

On the other hand, if we want to understand the role of DG in temporal lobe epilepsy, we cannot ignore GCP type 1 (characterized by significant granule cell loss), considering the significant correlation between granule cell loss in the DG and the same patient's regenerative capacity in vitro, as well as the same patient's ability to store and recall new memories.

Manuscript accepted for publication December 30, 2013

Department of Biomedical and NeuroMotor Sciences (DiBiNeM), University of Bologna, Section of Pathology “M. Malpighi”, Bellaria Hospital, Via Altura 3, 40139, Bologna, Italy. Email: gianluca.marucci@ausl. bologna.it

doi: http://dx.doi.org/10.4021/jnr260w
These considerations are not meant to be a criticism of indepth studies, but an overly restrictive approach, distinguishing, for example, GCD from bilamination of granule cell layer, could remain a matter of debate among neuropathologists, rather than offering a new useful tool to neurologists or neurosurgeons. In keeping with the histologic demonstration of an abnormal granule cell layer, the status of DG should no longer be considered as an accessory morphologic finding without significance in predicting epileptogenic outcome.

In conclusion, further investigations are needed, but the observations already available argue significantly for the association between favorable postsurgical outcome and granule cell pathology (type 1 and type 2). Therefore, the status of DG could help clinicians in predicting the postoperative outcome and planning a better follow-up schedule.

\section{Conflict of Interest}

None.

\section{References}

1. Blumcke I, Kistner I, Clusmann H, Schramm J, Becker AJ, Elger CE, Bien CG, et al. Towards a clinico-pathological classification of granule cell dispersion in human mesial temporal lobe epilepsies. Acta Neuropathol. 2009;117(5):535-544.

2. da Costa Neves RS, Jardim AP, Caboclo LO, Lancellotti C, Marinho TF, Hamad AP, Marinho M, et al. Granule cell dispersion is not a predictor of surgical outcome in temporal lobe epilepsy with mesial temporal sclerosis. Clin Neuropathol. 2013;32(1):24-30.

3. Thom M, Liagkouras I, Elliot KJ, Martinian L, Harkness W, McEvoy A, Caboclo LO, et al. Reliability of patterns of hippocampal sclerosis as predictors of postsurgical outcome. Epilepsia. 2010;51(9):1801-1808.

4. Marucci G, Rubboli G, Giulioni M. Role of dentate gyrus alterations in mesial temporal sclerosis. Clin Neuropathol. 2010;29(1):32-35. 